\title{
Storying the World: A posthumanist critique of phenomenological-humanist representational practices in mental health nurse qualitative inquiry
}

\begin{abstract}
The purpose of this paper is to build on my previously published critique of phenomenological-humanist representational practices in mental health nursing qualitative inquiry. I will unpack and trouble these practices from an explicitly posthumanist philosophical position on the basis of seminal posthumanist texts and my own single- and coauthored work. My argument will be that researchers in mental health nurse qualitative inquiry, who display a phenomenological-humanist narrative bent in their writing, continually endorse the validity of the institutional psychiatric assumptions, practices and ways of representing human psychological distress. These are all explicitly rejected in more critical forms of qualitative inquiry in mental health, including in my own work. I will conclude that the use of phenomenological-humanist representational practices, in mental health nursing and by implication and extension other healthcare disciplines, is un-ethical, un-empathic and morally compromised. This is because such practices present accounts of the worlds of mental health service users, survivors and carers that lack necessary and sufficient levels of criticality and context.
\end{abstract}

Keywords: Narrative Ethics, Mental Health, Nursing, Phenomenology, Qualitative Research, Narrative. 


\section{Introduction}

Over the last two decades, I have worked as a qualitative researcher, research supervisor, teacher, article and book writer and editor, and peer reviewer of qualitative texts for journals and publishing houses. As a narrative scholar, I have simultaneously promoted and critiqued the lived-experience paradigm in all of these contexts. I have done so partly in relation to my growing critical interest in mental health nurse researchers' phenomenological-humanist representations of the world.

Having previously challenged implicit philosophical assumptions apparent in such work, around 'authentic voice' related to 'lived-experience', from a poststructural researcher standpoint perspective (Grant, 2014), my aim in this paper is to extend this critique. On the basis of my argument that phenomenological-humanist representational practices in mental health nursing qualitative inquiry often lack adequate levels of theoretical and cultural reflexivity (Grant, 2014), I will further unpack and trouble these practices from an explicitly posthumanist philosophical position. I will do so on the basis of both posthumanist and related writing, and my own single- and co-authored publications that cohere with this philosophical standpoint.

Posthumanism, to be defined more fully later in this paper, assumes in brief that human subjective experience is plural, fragmented, unstable, incoherent and constantly shifting across time and space. It further assumes that human subjectivity is co-constituted by, and co-evolving with, other, non-human animals, and with material and non-organic entities and forces that both have and exert agency. This markedly contrasts with the ontoepistemological position resulting from the fusion of the Husserlian phenomenological 
assumption of essential structures of lived experience giving meaning to the world with the tenets of contemporary liberal humanism. This fusion, which I describe as phenomenologicalhumanism, privileges human choice and progress in a world generally regarded as having no other purpose and function than serving human agency.

My concern is not with the extent that authors who use phenomenological-humanist representational practices maintain fidelity with Husserlian and other, related, key philosophical principles (Paley, 1997). Moreover I should qualify that my critique will not extend to the kinds of post-Husserlian developments from phenomenology that derive from the work of Heidegger, Gadamer and others (Chang and Horrocks, 2008). This hermeneutic tradition broadly fits with my critical narrative frame of reference in eschewing objectivism, and emphasising the importance of context and the co-creation by researchers and participants of situated, inter-subjective stories of the world.

In contrast, I have problems with appropriations of descriptive phenomenology deriving from Husserl's writing. This is because of the implicit objectivism in these appropriations in claiming to identify and uncover the 'essential structures' of participants' lived experiences (Lowes and Prowse, 2001). These structures are presented as free of both social and historical context and researcher contamination, having being garnered through a systematic, quasi-scientific process whereby previous knowledge, presuppositions and prejudices are kept at a distance. All of this is assumed to accord such essential structures a level of ontological legitimacy and coherence that I have always found deeply unconvincing. 
Along with others (eg Lopez and Willis, 2004), I am specifically critically interested in the ways in which qualitative researchers in mental health nursing display a phenomenologicalhumanist narrative bent (to be clarified below) through a more or less loose and insufficiently scrutinised appropriation of such Husserlian descriptive assumptions and principles.

More specifically, in relation to my concerns as a narrative scholar and researcher, I am interested in the ways in which they use these assumptions and principles to story the world in their writing and the consequences of these stories. For example, it seems to me that taken for granted binaries prevail in mental health nursing phenomenological-humanist qualitative inquiry,. The frequent use of terms such as 'self' and 'identity' usually imply coherent identities separate from the world which is assumed to be outside of, and relatively unrelated to, self. The implicitly 'mentally well' are divided from the 'mentally ill', as are the (well) researchers from (ill) participants. The absence of a critically reflexive commentary around the assumptions underpinning these terms in the context in which they appear makes it seem as if their use is unproblematic. In this regard, readers of these articles are implicitly invited to take for granted that these assumptions and terms are necessary and sufficient to accurately and fairly represent the world, topic and people under discussion, in ways that transcend culture, time and place.

\section{Representational insularity}

Related to the use of these terms in research narratives and to the kinds of worlds they speak into existence, the people represented in these articles are often portrayed as existing in special kinds of macro-isolation units devoid of real life contexts. At an environmental level, participants and researchers are portrayed as separated and insulated from messy and 
contradictory human organisational and social cultures. Both groups apparently often live in power-neutral or power silent, a-political environments, where healthcare organisations are represented as benign unproblematic backdrops to practice. At a cultural level, the constant representation of dominant societal and professional beliefs around the assumed existence of 'mental illness', obscures work that challenges this. From the contemporary critical mental health paradigm that I also work and write within, the disease model for making sense of the extremes of human misery is both scientifically unsupportable and oppressive (Grant, 2015; in press).

From critical social and human science, and more specifically posthumanist perspectives, phenomenological-humanist work seems to me therefore to be constantly ethicallycompromised. It representationally insulates the people storied in it from the above contexts and worlds that are fundamental to their lives, and from knowledge of the forms of, already robustly challenged, cultural oppression in which their lives are inscribed.

Even greater levels of representational insularity are apparent in more explicitly Husserlianinformed research articles in which the assumed privileged interior nature and qualities of such de-contextualised selves are often represented in quasi-religious terms. In the sacred quest for pure descriptions of lived experience of individual and collective perceptions of the world, researchers frequently write in a kind of awe-inspired biblical epistle-narrative form, in ways lacking in both critical distance and irony. This illustrates their apparent engagement in a fundamentalist quest for original untainted knowledge:

Phenomenological reduction is a return to original awareness... (In)... the recovery 
of a pure description of the phenomenon ... (describing) with scientific exactness, the life of consciousness in its original encounter with the world... Husserl (1931)...challenged individuals to go 'back to the things themselves' to recover....original awareness

(Rooney, 2009, 78, my brackets)

The insufficient levels of critical scrutiny paid to the cultural and historical basis for these terms, in the narrative and representational forms in which they are used, combine with the dubious ethical issues around the consequences of the world they story into existence. All of this seems to me to betray representational habits that beg critical scrutiny. These habits arguably derive from phenomenological-humanistic philosophy cohering around particular currently culturally hegemonic and normative, but arguably outmoded, notions of what it means to be human in the world in a mental health nursing research context. I will argue below that these habits are understandable in the face of an onto-epistemological legacy that stretches back over two and a half thousand years. It is therefore not surprising that many phenomenological-humanist nurse researchers neither recognise nor acknowledge - at least in print - that their writing is based on insufficiently questioned, longstanding habits. Rather, their work is regularly presented as reflecting timeless, transcendent, universal, foundational and essential psychological and material realities.

\section{Phenomenological-Humanism}

My choice of the term 'Phenomenological-Humanism' collapses the ways in which Husserlian phenomenological assumptions have been appropriated as described above with the tenets of contemporary liberal humanism. The assumption of human essential structures of lived 
experience giving meaning to the world deriving from the work of Husserl (1931), which are uncovered in descriptive phenomenological research, seems to closely relate to both humanism in its more abstract historical sense and to liberal humanism. From the historical perspective of Hurari (2011), human exceptionalism emerged as the assumption that Homo sapiens possess a unique and privileged nature relative to all other animals and material phenomena. Hurari argues that liberal humanism positions this nature as 'humanity' - a unique and sacred quality residing within each human. From a liberal humanist perspective in affinity with Husserlian phenomenological assumptions, the inner core of each individual is assumed to provide meaning about the world, and constitute the source of all experiential authority.

\section{The Vitruvian model}

How did beliefs about the ontologically privileged status of humanity and humanness originate, take cultural hold and develop through time? Braidotti (2013) provides a compelling historical analytic line of inquiry to address this question. In her view, da Vinci's $15^{\text {th }}$ century painting of Vitruvian Man represents the classical ideal of human embodiment, originally emerging from the pre-Socratic philosophical world as both the 'measure of all things' and the ideal of bodily perfection. 'Mens sana in corpore sano', translates as a 'sound mind in health body' and symbolises the capacity of humans to pursue individual and collective perfection.

Braidotti argues that the fact that this is conveyed through and in an image of a white, European male of healthy and physically fit appearance, is an emblematic of the subsequent 
malestream shaping of Enlightenment-derived humanism. This implicitly privileged androcentricity (male-centredness) over anthropocentricity (human-centredness), simultaneously collapsing the latter into the former as assumed biologically foundational givens, beyond question. As a result, a rational, morally progressive enterprise took hold, within which a particular ideal type of human being dominated European cultural development.

Braidotti maintains that this dominance has endured through the centuries to our current times, changing in contextual meaning as a function of its constant re-inscription within shifting cultural formations. She argues in support of this point that as a cultural emblem the Vitruvian model informed the development of Enlightenment values in the $18^{\text {th }}$ and $19^{\text {th }}$ century. This re-worked the earlier ideals of classical antiquity and the Italian Renaissance in the service of Enlightenment cultural imperatives. Shaping up as the civilising cultural standard at individual and community levels, the idea of 'Europe' gradually cohered around the assumed universalizing powers of self-reflexive reason. Vitruvian ideals developed into a hegemonic cultural model, where 'Europe' meant not simply a geopolitical location but also a universalising mental attribute that had utility as a gold-standard colonising template.

According to Braidotti, this latter meaning enabled Husserl (1970) to passionately defend Eurocentric reasoning powers as transcendent Humanistic universalism in the 1930s, in reaction to the threats of emerging fascism. Braidotti argues that in its rejection of cultural and historical contingency in favour of a universalising model of civilising practice, Husserl's espoused Eurocentrism saturated theoretical, institutional and pedagogic practices. In becoming steadily imperial and colonial, the Eurocentric liberal humanist paradigm 
conveniently functioned to make sense of the world's peoples as 'other' and to subjugate groups of them in the service of both geopolitical and academic interests.

Braidotti's posthumanist historical analysis makes intelligible the unfortunate actual and potential consequences of liberal humanism's gradual emergence as an imperial and colonising tool. These consequences give the lie to its more rationalised, professional and cultural appropriation as a form of universal virtue ethics for making sense of and being respectful to people and developing communities of understanding. This appropriation has been evident in healthcare for decades in phenomenological-humanist qualitative research practices.

\section{Challenging liberal humanist othering representational practices}

Braidotti (2013) argues that liberal humanism, in both its geopolitical and research application, is imperial in fulfilling the assumed expansionist rights and interests of some powerful groups while denying the rights and interests of less powerful others. To the extent that it is colonising in both geopolitical and research terms, it engages in 'othering' practices. This signals judgements of inferiority and less-than humanness, made about some people and populations. In this analytic context, phenomenological-humanist representational practices predicated on 'well-sick' and 'normal-pathological' terms, no matter how well-intentioned, arguably often condemn to the status of 'othered' all those who fail to measure up to normative, hegemonic healthcare cultural standards. 
My single- and joint-authored qualitative and theoretically driven work has challenged these binarying representational practices. For example, our narrative inquiry work explores the ways in which institutional psychiatry often imposes scientifically deeply flawed (Grant, 2015; Smith and Grant, in press), and pejorative narratives and labels on people in the name of 'treatment' and 'care' in the UK institutional psychiatric system. This serves to maintain an indefensible cultural binary between 'mental illness' and 'wellness' (Grant, 2015; Smith and Grant, in press).

As I will discuss in more detail later, we have used critical, highly reflexive and contextual storytelling and dialogical narrative analysis to show how mental health 'survivors' often restory themselves in ways independent of institutional psychiatry. They do so in order to achieve a degree of emancipation and distance from these normative practices and services (eg Grant and Leigh-Phippard, 2014; Grant et al., 2015). Moreover, in framing some of this work within a Queer Theoretical paradigm (Grant, 2015; Grant and Leigh-Phippard, 2014; Grant et al., 2015; Zeeman et al., 2014a,b), we have discussed and provided exemplars of the ways in which healthcare workers, researchers and service users and carers can re-inscribe aspects of being human - often pathologised and stigmatised at cultural, institutional and disciplinary levels - within liberatory structures of difference rather than normative biomedical and cultural structures of 'ill health', 'pathology' or 'deviance'.

Those who are othered, who fall short of culturally normative standards of acceptability, are often either brought into line with those standards or excluded through discrimination and stigmatisation. Examples of this are legion in a mental health context, and specifically apparent in the work cited above and in our earlier collection of mental health user, carer and 
survivor narratives (Grant et al., 2011). At an applied disciplinary level, this has crucial implications for nursing qualitative research. Phenomenological-humanist representational practices often simultaneously assume the validity of biomedical models of extreme psychological distress as a legitimising back story or master narrative. From a critical posthumanist perspective, the use of terms such as 'mental illness', 'symptoms' and 'schizophrenia' function in the service of maintaining cultural hegemony and normativity to the disadvantage of some people and populations.

The phenomenological-humanist binary apparent in 'researcher-researched' and 'professional-patient' arguably also contributes to maintaining such a cultural divide. This binary has been undermined recently in my own work and the work of a colleague in relational autoethnographic writing where the researchers and the researched are the same people, who celebrate a postcolonial hybrid identity status as both mental health researchersprofessionals and service-users or survivors of the UK institutional mental health system (Grant et al., 2015; Williams, 2015).

\section{Posthumanism}

In the light of the argument to this point, far from being transcendent, the 'human' of phenomenological-humanism has the status of a culture-, profession- and paradigm-serving, historically contingent construct. This construct has settled over the centuries into a kind of unquestioned social convention in the public and academic consciousness - in short, a habit of thinking about, acting towards and representing people in their worlds that, although it has paid cultural dividends over the centuries, has long exceeded its contemporary relevance. 
Barad (2007), Butler $(1990)$ and Foucault $(1995,1998)$ reject the fundamental assumptions that form the basis of this habit set. The idea that a human identity is essentially, singularly and coherently formed prior to its inscription within separate sociocultural and material formations is robustly contested. These posthumanist thinkers view the subjective experience of being human as plural and fragmented; as socially, geographically, materially, organically, ecologically and temporally contingent and unstable; as co-evolving with sociocultural and material formations; and as produced within, rather than producing, meaning, performance, practice and multiple representational structures, or 'discourses', which constantly change in line with the complex reconfiguration of cultures, times and places.

In illustration of this point, Butler (1990) argue that we should think more in terms of subjectivity rather than identity. Whereas 'identity' in a liberal humanist sense suggests individual agency relatively free from the constraints of culture and social and material structures, 'subjectivity' implies the dual sense of being constituted and produced within and by the cultural, social and material, while having sufficient agency to 'answer back' and relatively resist such discursive shaping forces. From this perspective, phenomena like gender, sexuality or mental health status are not attributes or essential properties of people, but a kind of becoming or performed activity, reinforced through repeated action and conformity or resistance to cultural pressures.

Foucault argues similarly throughout his writing, asserting that different historical conditions call forth different kinds of subjectivities. In Foucault's terms, this occurs as a result of the constant repetition of specific acts in the context of institutional and cultural practices. This both empowers bodies, and ensures that individuals are policed and police themselves in 
their lives and relationships to ensure relative conformity to normative cultural practices (Foucault, 1998).

It is important at this point to stress, after Barad (2007) that subjective agency in relation to cultural practices and discourse does not imply a separation between humans and human culture and the material and non-material world in posthumanist thinking. Barad employs the term 'material-discursivity' to highlight the fact that the material and non-material world produces, co-evolves with and is co-implicated in human meaning, experience and action.

In this sense, her parallel use of the term 'intra-action' contrasts with what is normally, and in phenomenological-humanist terms, regarded as inter-action. Interaction presumes the prior, transcendent, existence of independent entities. Intra-action does not. Qualitative researchers are bound up, inseparably, in all that they study, at all levels, so distinctions between subjects and object in the research process are enacted in, rather than inherent properties of, the world.

In this sense and context, 'agency' is a dispersed phenomenon, rather than the property of individual human actors. The non-human and material world matters in an active sense. Buildings, technology and non-human animals are very much part of intra-action and the enactment of reality. From a posthumanist perspective therefore, agency is not a property or attribute, but the ongoing, unstoppable reconfigurings of the world, which is constantly engaged in the process of articulating itself differently. 
So, the reality of the world is less to be found in the essential identities of individuals in a phenomenological-humanist representational sense, and more in sets of time- and placebound discursive-material practices. In this context, reported 'lived-experience' retains its importance for mental health nursing qualitative inquiry, although not in the 'naïve realist' phenomenological-humanist sense of literally revealing the essential meaning characteristics of participants' lives (Grant, 2014). Rather, participants' and researchers' narratives give access to the ways in they, as are all of us, are more or less caught up in enacted structures of power emanating from their constant inscription within multiple and often contradictory cultural discourses, sometimes called 'master narratives'.

It is not surprising, therefore, that the stories told by participants in qualitative health research articles can range from displaying, replicating and re-circulating these master narratives, to contesting and violating them (Frank, 2015; Grant et al., 2015). Recent examples of this in my own writing display the ways in which mental health survivors have resisted staying 'narratively entrapped' in diagnostic and pejorative psychiatric narratives by 'restorying' themselves through the use of reflexive autoethnographic writing methods (Grant et al., 2013). This has helped them to resist what they perceived as the oppressive colonization of their identities and lives by institutional psychiatric services and practices, in favour of exercising a greater degree of freedom over their future existential choices (Grant and Leigh-Phippard, 2014; Grant et al., 2015). To develop a point made earlier, these choices often explicitly reject the normative expectations imposed on mental health service users, which are enshrined in mental health nursing practice at policy, professional and research levels. Survivors may, for example, refuse diagnoses, psychiatric medication, and withhold information from psychiatrists in the interests both of maintaining personal integrity and 
keeping institutional psychiatric services at a safe distance (Grant and Leigh-Phippard, 2014; Grant et al., 2015).

\section{Concluding comments: ethical challenges in representational practices}

I have previously argued that much qualitative inquiry in mental health nursing, - especially that conducted in the name of uncovering and describing 'lived experience' - portrays the opposite of survivor re-storying (Grant, 2014). It does so in a kind of bland conformity, where research practices and representational conventions continually endorse the validity of the institutional psychiatric assumptions that are explicitly rejected in more critical forms of qualitative inquiry in mental health (Grant, 2015; Smith and Grant, in press).

In the qualitative themes in much of the phenomenological-humanist research I read, a kind of constant and reassuring rehearsal of the familiar and the expected is apparent. This functions simultaneously as a form of avoidance - of the nature, effects and impact of power, politics and contingent nature of life, on people suffering the extremes of human misery, either directly or as carers, and other people engaged in researching this suffering. Thus phenomenological-humanist accounts constitute a pretence of representing the world with much of its interesting, dynamic and disturbing aspects airbrushed out. Such stories are deficient in the levels of criticality that I believe are represented in both my own work, and the work of my colleagues and associates, and in paying necessary and sufficient attention to the contexts of the lives of mental health service users and survivors (Grant, 2015, Smith and Grant, in press), and carers (Klevan et al., 2016). 
Moreover, by privileging human agency to the extent that this obscures social and material shaping forces, phenomenological-humanist representational practices in qualitative inquiry in mental health nursing and, by extension, other health disciplines, are arguably fundamentally unethical. The act of ignoring the world, as though it could go away, and pretending to a supposedly limitless capacity of agency and lived experience to transcend and overcome social and material structures, or ignoring the importance of these structures relative to the assumed significance of lived experience, feeds back into curricular and other practices in mental health which perpetuate the normative and the oppressive.

This representational stance is also arguably un-empathic to the extent that it colludes with the idea of locating mental health difficulties exclusively within individuals. This ignores the role of social, material, organisational, professional, corporate and ideological practices, in both causing and worsening the experience of psychological distress among mental health service users, carers and survivors (Grant, 2015; Smith and Grant, in press). Such neglect, apparent in qualitative work that, because of the insufficiently examined philosophical assumptions reflected in its representational practices, constantly needs to respond to the following set of charges: it is naïve realist, de-contextual, philosophically and theoretically under-scrutinised, and insular and un-reflexive at mental health professional, and research disciplinary and representational levels (Grant, 2014).

Finally, phenomenological-humanist accounts do not fare well in the broader context of narrative ethics. At worst, through lacking context and criticality, they present a world where users, survivors, carers and significant others in their lives are stripped of vitally important family and community meanings that need to be preserved in both research and related 
recovery interventions. Because these meanings accord sense, nuance and importance to the worlds such people and communities live in, representationally depriving them of knowledge of these worlds, and of the power relations that govern them, amounts to a form of narrative violence. Such writing therefore falls foul of 'guilt by omission.' This is a troubling and serious issue: Loy (2010) reminds us that different stories told about the world have different consequences, and this is by no means a morally neutral state of affairs.

\section{References:}

Barad K. (2007) Meeting the Universe Halfway: Quantum Physics and the Entanglement of Matter and Meaning. Duke University Press, Durham and London.

Braidotti R. (2013) The Posthuman. Polity Press, Cambridge.

Butler J. (1990) Gender Trouble: Feminism and the Subversion of Identity. Routledge, New York.

Chang K.H. \& Horrocks S. 2008. Is there a place for ontological hermeneutics in mentalhealth nursing research? A review of a hermeneutic study. International Journal of Nursing Practice, $14,383-390$.

Foucault M. 1995. Discipline \& Punish. The Birth of the Prison. Random House, New York and Toronto.

Michel Foucault, (1998) The History of Sexuality Vol. 1: The Will to Knowledge. London, Penguin. 
Frank AW. 2015. From sick role to narrative subject: An analytic memoir. Health. Health (London). 2016 Jan;20 (1):9-21. doi: 10.1177/1363459315615395. Epub 2015 Nov 18.

Grant A. 2014. Troubling 'lived experience': a post-structural critique of mental health nursing qualitative research assumptions. Journal of Psychiatric and Mental Health Nursing, 21, 544-549.

Grant A. (2015) Demedicalising misery: Welcoming the human paradigm in mental health nurse education. Nurse Education Today, 35, e50-e53.

Grant A., Short N.P. \& Turner L. (2013) Introduction: Storying Life and Lives. In: Contemporary British Autoethnography (eds. N. Short N., L. Turner \& A. Grant) pp. 1-16. Sense Publishers, Rotterdam.

Grant A. \& Leigh-Phippard H. (2014) Troubling the normative mental health recovery project. The silent resistance of a disappearing doctor. In: Queering Health: Critical challenges to normative health and healthcare (eds. L. Zeeman, K. Aranda \& A. Grant) pp. 100-115. PCCS Books, Ross-on-Wye.

Grant A., Biley F. \& Walker H. (eds) (2011) Our Encounters with Madness. PCCS Books, Rosson-Wye. 
Grant A., Zeeman L. \&Aranda K. (2015) Queering the relationship between evidence-based mental health and psychiatric diagnosis: Some implications for international mental health nurse curricular development. Nurse Education Today, 35, e18-e20.

Grant A., Leigh-Phippard H. \& Short N. (2015) Re-storying narrative identity: a dialogical study of mental health recovery and survival. Journal of Psychiatric and Mental Health Nursing, 22, 278-286.

Hurari Y.N. (2011) Sapiens: A Brief History of Humankind. Vintage Books, London.

Husserl E. (1931) Ideas: An Introduction to Pure Phenomenology.(Translated by W Gibson). Macmillan, New York.

Husserl E. (1970) The crisis of European Sciences and Transcendental Phenomenology. Indiana University Press, Evanston, IL.

Trude Klevan, Larry Davidson, Ruud Torleif \& Bengt Karlsson (2016): “We are Different People". A Narrative Analysis of Carers' Experiences with Mental Health Crisis and Support from Crisis Resolution Teams, Social Work in Mental Health, DOI:

$\underline{10.1080 / 15332985.2015 .1133471}$ http://dx.doi.org/10.1080/15332985.2015.1133471

Lopez K.A., Willis D.G. (2004) Descriptive Versus Interpretive Phenomenology: Their Contributions to Nursing Knowledge. Qualitative Health Research, 14, 5, 726-735. 
Lowes L. \& Prowse M.A. (2001) Standing outside the interview process? The illusion of objectivity in phenomenological data generation. International Journal of Nursing Studies, 38, 471-480.

Loy D.R. (2010) The World is made of Stories. Wisdom Publications, Boston.

Paley J. (1997) Husserl, phenomenology and nursing. Journal of Advanced Nursing, 26, 187193.

Rooney C. (2009) The meaning of mental health nurses experience of providing one-to-one observations: a phenomenological study. Journal of Psychiatric and Mental Health Nursing, $16,76-86$.

Smith, Steve, Grant, Alec, The corporate construction of psychosis and the rise of the psychosocial paradigm: Emerging implications for mental health nurse education. Nurse Education Today (2016), doi: 10.1016/j.nedt.2016.01.007

Williams S. (2015) Recovering from Psychosis: Empirical Evidence and Lived Experience. Routledge, London and New York.

Zeeman L., Aranda K. \& Grant A. (eds). 2014. Queering Health: Critical challenges to normative health and healthcare. PCCS Books, Ross-on-Wye. 
Zeeman L., Aranda K. \& Grant A. (2014) Queer Challenges to Evidence-based Practice.

Nursing Inquiry, 21, 2), 101-111. 